\title{
New dysmorphic features in Rubinstein-Taybi syndrome
}

\author{
Department of \\ Pediatrics, Lincoln \\ Medical and Mental \\ Health Center - New \\ York Medical College, \\ Bronx, NY 11206, \\ USA. \\ D Kanjilal \\ M A Basir \\ B K Rajegowda \\ R Lala \\ A Nagaraj
}

Division of Genetics,

The Long Island

College Hospital,

SUNY Health Science

Center, Atlantic

Avenue at Hicks

Street, Brooklyn, NY

11201 , USA.

R S Verma

Correspondence to

Dr Verma.

Received 2 December 1991.

Accepted 13 January 1992.

\author{
Debasis Kanjilal, Mir A Basir, Ram S Verma, Benamanahalli K Rajegowda, Rasila \\ Lala, Anasuya Nagaraj
}

\begin{abstract}
We report a new case of RubinsteinTaybi syndrome with a hypoplastic right kidney, persistent pulmonary hypertension, and mitral valve regurgitation. Other pertinent features included broad thumbs, broad big toes, syndactyly of the third and fourth fingers bilaterally, beaked nose, broad columella of the nose, patent ductus arteriosus, and motor and mental retardation. The testes were descended. The 3 month old patient had delayed motor and mental development corresponding to a 1 month old infant. (₹ Med Genet 1992;29:669-70)
\end{abstract}
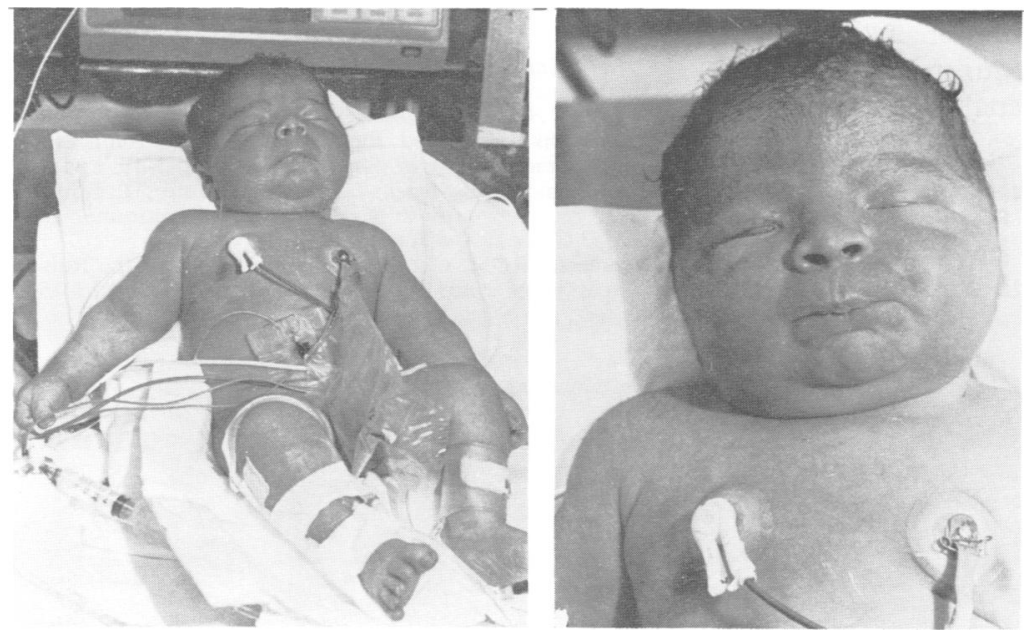

Figure 1 Proband at birth showing typical feature of Rubinstein-Taybi syndrome.
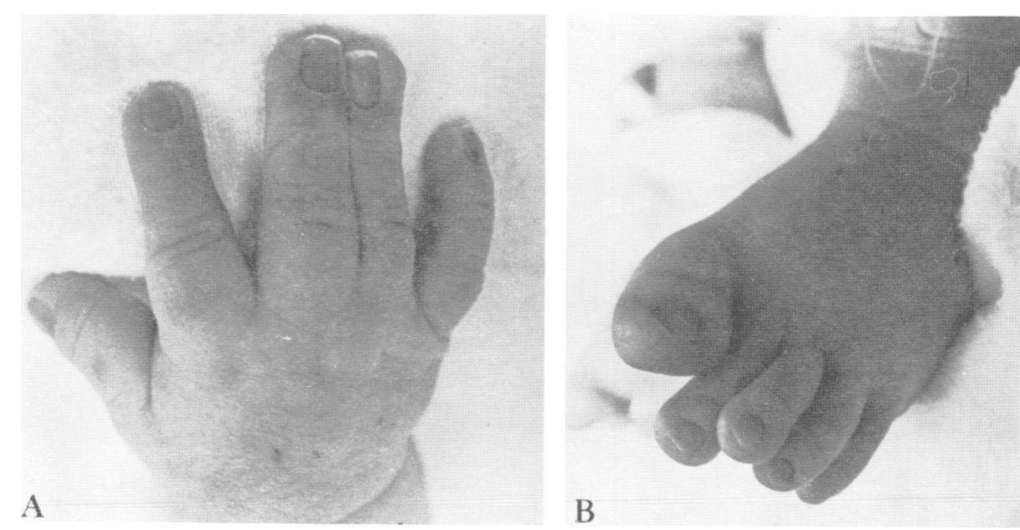

Figure 2. (A) Syndactyly of third and fourth finger. (B) Broad big toes and overlapping second and third toes.
In 1963 Rubinstein and Taybi ${ }^{1}$ first delineated a syndrome characterised by broad thumbs, broad toes, mental and motor retardation, cardiovascular and renal anomalies, beaked nose, and downward slanting palpebral fissures. We report new findings in RubinsteinTaybi syndrome with hypoplastic right kidney, persistent pulmonary hypertension, and mitral valve regurgitation. Other pertinent features included broad thumbs, broad big toes, syndactyly of the third and fourth fingers bilaterally, beaked nose, broad columella of the nose, patent ductus arteriosus (PDA), and motor and mental retardation. This combination of features has not previously been reported.

\section{Case report}

This male infant (fig 1) was born at term by normal spontaneous vaginal delivery to a 39 year old mother. The father was 34 years old. The pregnancy was uneventful with the exception of urinary tract infections at four months of gestation. The Apgar scores were 7 at one minute and 9 at five minutes, birth weight was $4390 \mathrm{~g}$ (90th centile), head circumference $35 \mathrm{~cm}$ (50th centile), and length $50 \mathrm{~cm}$ (50th centile). Pertinent physical findings included broad thumbs with radial deviation, syndactyly of the third and fourth fingers bilaterally, broad big toes (fig 2), beaked nose with broad columella, and a grade $3 / 4$ holosystolic murmur heard best at the left sternal border, fourth intercostal space. The remaining physical findings were within normal limits.

The patient was clinically asymptomatic until 2 hours of life when he developed hypoglycaemia and tachypnoea. The hypoglycaemic condition was resolved with glucose infusion but tachypnoea persisted, requiring $45 \%$ oxygen therapy for hypoxia. The initial chest radiograph showed normal lungs and heart but a few hours later cardiomegaly with normal pulmonary vasculature was noted. Preductal and postductal blood gas analysis showed persistent pulmonary hypertension (PPHN). Ecocardiogram showed PDA, intermittent right to left ductal shunt, right ventricular dilatation, and mitral and tricuspid regurgitation. PPHN required oxygen therapy for seven days. Cardiac catheterisation done later showed mitral regurgitation and PDA with normal $\mathrm{LV}$ and 
RV function. In order to rule out any other associated anomalies routine head ultrasound was performed and was normal. Renal ultrasound showed a normal left kidney but a small $(3 \mathrm{~cm})$ right kidney; later a renal scan showed that the left kidney had $80 \%$ function and the right kidney had $20 \%$ function. Intravenous pyelography (IVP) showed a normal left kidney and a hypoplastic right kidney with a reduced number of calyces but no hydronephrosis. The patient left the hospital after 23 days of life without any complications.

At about 2 months of age, the patient was admitted to the paediatric ward with respiratory distress and growth failure. The patient's weight was $4.4 \mathrm{~kg}$ ( 25 th centile), head circumference was $36 \mathrm{~cm}$ ( $<5$ th centile), and length $55.8 \mathrm{~cm}$ (50th centile). At 3 months of age the patient had progressively delayed growth and motor and mental development which corresponded to 1 month of age (length 5 th centile, weight 10 th centile, head circumference 5 th centile).

Amniocentesis was performed on the mother because of advanced maternal age. Cytogenetic findings with $G$ banding showed an apparently normal $46, \mathrm{XY}$ karyotype in her amniotic fluid. The normal chromosomal analysis was confirmed in the child at birth.

\section{Discussion}

Our patient has a unique presentation of Rubinstein-Taybi syndrome with hypoplastic right kidney, persistent pulmonary hypertension, and mitral valve regurgitation. He did not present with any renal problem but a hypoplastic right kidney was found on routine ultrasound and was confirmed by renal scan and IVP. We strongly advise that genitourinary systems should be evaluated thoroughly in all patients with Rubinstein-Taybi syndrome. Persistent pulmonary hypertension in our patient could be the result of hypoxia. Although mitral valve regurgitation persists, left ventricular function remains normal and no left ventricular outflow obstruction has been noted. The patient also developed a urinary tract infection around 2 months of age which is not an unusual presentation. ${ }^{2}$ The patient had delayed mental and motor development. Growth was falling off, which is usual in this syndrome.

Other pertinent features included broad thumbs, broad big toes, bilateral syndactyly of the third and fourth fingers, beaked nose, broad columella of the nose, and PDA. In previous reports, chromosomal abnormalities included $\operatorname{der}(2), \operatorname{del}(14 q), \operatorname{del}(10 p$ and $12 p)$, and $\operatorname{del}(\mathrm{lq}) \cdot{ }^{3}$ However, the present case has an apparently normal karyotype. Despite the clear clinical presentation of the RubinsteinTaybi syndrome, the genetic basis remains obscure. Hennekam et $a l^{4}$ recently reviewed published reports and suggested that an autosomal dominant mutation could be the most probable cause; a consistent chromosome abnormality has not been localised. ${ }^{5}$ A number of studies have found cytogenetic heteromorphisms (table IX, Rubinstein ${ }^{3}$ ) but our case had no variants. To date, more than 600 patients have been reported in 300 articles. $^{2}$ However, our patient has a unique presentation which has not been previously reported.

1 Rubinstein JH, Taybi H. Broad thumb and toes and facial abnormalities: a possible mental retardation syndrome. $\mathrm{Am}$ f Dis Child 1963;105:588-608.

2 Hennekam RCM. Bibliography on Rubinstein-Taybi syndrome. Am F Med Genet 1990;6(suppl):77-83.

3 Rubinstein JH. Broad thumb-hallux (Rubinstein-Taybi) syndrome. Am f Med Genet 1990;6(suppl):3-16.

4 Hennekam RCM, Stevens CA, Van de Kamp JJP. Etiology and recurrence risk in Rubinstein-Taybi syndrome. $A m \mathfrak{f}$ and recurrence risk in Rubinstein-1

5 Hennekam RCM. Chromosomal localization of the Rubinstein-Taybi syndrome. Am $\mathcal{F}$ Med Genet 1991;38:634-5. 